Article

\title{
Profiling of Fatty Acids Composition in Suet Oil Based on GC-EI-qMS and Chemometrics Analysis
}

\author{
Jun Jiang ${ }^{1,2}$ and Xiaobin Jia ${ }^{1,2, *}$
}

1 Affiliated Hospital on Integration of Chinese and Western Medicine, Nanjing University of Chinese Medicine, Xianlin Avenue 138\#, Xianlin University City, Nanjing 210023, China; E-Mail: xuyan9323@126.com

2 Key Laboratory of New Drug Delivery System of Chinese Meteria Medica, Jiangsu Provincial Academy of Chinese Medicine, 100\# Shizi Road, Nanjing 210028, China

* Author to whom correspondence should be addressed; E-Mail: xiaobinjia_nj@126.com; Tel.: +86-25-8563-7809.

Academic Editor: Bing Yan

Received: 19 August 2014 / Accepted: 20 January 2015 / Published: 28 January 2015

\begin{abstract}
Fatty acid (FA) composition of suet oil (SO) was measured by precolumn methylesterification (PME) optimized using a Box-Behnken design (BBD) and gas chromatography/electron ionization-quadrupole mass spectrometry (GC-EI-qMS). A spectral library (NIST 08) and standard compounds were used to identify FAs in SO representing $90.89 \%$ of the total peak area. The ten most abundant FAs were derivatized into FA methyl esters (FAMEs) and quantified by GC-EI-qMS; the correlation coefficient of each FAME was 0.999 and the lowest concentration quantified was $0.01 \mu \mathrm{g} / \mathrm{mL}$. The range of recovery of the FAMEs was $82.1 \%-98.7 \%$ (relative standard deviation $2.2 \%-6.8 \%$ ). The limits of quantification (LOQ) were $1.25-5.95 \mu \mathrm{g} / \mathrm{L}$. The number of carbon atoms in the FAs identified ranged from 12 to 20; hexadecanoic and octadecanoic acids were the most abundant. Eighteen samples of SO purchased from Qinghai, Anhui and Jiangsu provinces of China were categorized into three groups by principal component analysis (PCA) according to the contents of the most abundant FAs. The results showed SOs samples were rich in FAs with significantly different profiles from different origins. The method described here can be used for quality control and SO differentiation on the basis of the FA profile.
\end{abstract}


Keywords: suet oil (SO); composition profiles; fatty acids (FAs); GC-EI-qMS; chemometrics analysis

\section{Introduction}

Suet oil (SO), a fatty oil obtained from the domestic goat (Capra hircus Linnaeus) or sheep (Ovis aries Linnaeus), has been used in the food industry [1] and the medicine industry [2]. SO is rich in unsaturated and saturated fatty acids (FAs) [3], which are involved in a number of important physiological processes. They provide energy to the cell and act as substrates in the synthesis of fats, lipoproteins, liposaccharides and eicosanoids [4]. Furthermore, SO can be used as an excipient for enhancing the efficacy of traditional Chinese medicines such as Epimedium (Berberidaceae). It was hypothesized that the beneficial effects of Epimedium could be attributed to promotion of the intestinal absorption of drugs by the formation of micelles owing to the action of its FA ingredients [5]. The quality of SO can affect safety and efficacy for clinical patients. There has been little research on the FA composition of SO, however, and there are quality control difficulties in the production of SO. It is important to establish qualitative and quantitative analytical methodology for determining the FA composition of SO.

To date, the methods used for separation and measurement of FAs are mainly chromatographic, including thin-layer chromatography [6], high-performance liquid chromatography [7,8], gas chromatography [9-11], supercritical fluid chromatography [12] and liquid chromatography with tandem mass spectrometry [13-16]. These methods cannot identify major chemical components rapidly and accurately. However, the gas chromatography/electron ionization-quadropole mass spectrometry (GC-EI-qMS) [17-20] technique coupled with the use of a professional database (NIST 08) can identify many compounds directly and accurately according to their fragment ions and abundance ratio [21-23]. In addition, GC-EI-qMS used in the selective ion monitoring (SIM) can identify target compounds rapidly and accurately despite interference from impurities [24], which is especially useful for the analysis of a lipid-based matrix, including SO.

FAs need to be derivatized before they can be analyzed by GC-MS because they have boiling points, which make gasification difficult. In many precolumn derivative methods [25], FAs are normally precolumn methylesterified (PME) into FA methyl esters (FAMEs) [26]. To ensure optimum conditions for methylesterification, the influence of important experimental parameters affecting the efficiency of methylesterification, including methyl reagent volume, temperature and time, were investigated using a Box-Behnken design (BBD) [27,28]. During optimization, the total peak area of the identified FAs was used to select the best conditions. This study developed and validated a method for the qualitative and quantitative profiling of the FA content in SOs for the first time.

SOs have been used widely in medicinal and culinary areas, but their authentication and standardization have encountered some problems owing to deliberate contamination with other animal or vegetable oils. It is difficult to identify the origins and species of SO accurately on the basis of appearance and morphology. Furthermore, SOs from different species or from different regions are not of uniform composition. In this study, a total of 18 batches of SO collected from three provinces in China were 
analyzed by GC-EI-qMS to determine their FA compositions and principal component analysis (PCA) was used to evaluate and classify these samples.

\section{Results and Discussion}

\subsection{Optimal Results and Statistical Analysis of Precolumn Methylesterified (PME)}

By retaining only the factors statistically significantly different at $p \leq 0.05$, the following final equation in terms of uncoded factors was obtained:

Total peak area $=+3.954 \times 10^{9}+9.987 \times 10^{8} \mathrm{~A}+1.196 \times 10^{9} \mathrm{~B}+9.163 \times 10^{8} \mathrm{C}+1.099 \times 10^{9} \mathrm{AB}+$ $8.977 \times 10^{8} \mathrm{AC}+9.306 \times 10^{8} \mathrm{~B}-1.596 \times 10^{9} \mathrm{~A}^{2}-1.232 \times 10^{9} \mathrm{~B}^{2}-1.452 \times 10^{9} \mathrm{C}^{2}$.

In all, $25 \mathrm{FA}$ species can be identified from the chromatogram shown in Figure 1A. Comprehensive test results for response surface plots (3D) and contour plots (2D) show the total peak area was a maximum when the methylesterification conditions were: reagent volume $10 \mathrm{~mL}$; temperature $60{ }^{\circ} \mathrm{C}$; and time $10 \mathrm{~min}$ (Figure 1C).

(A)

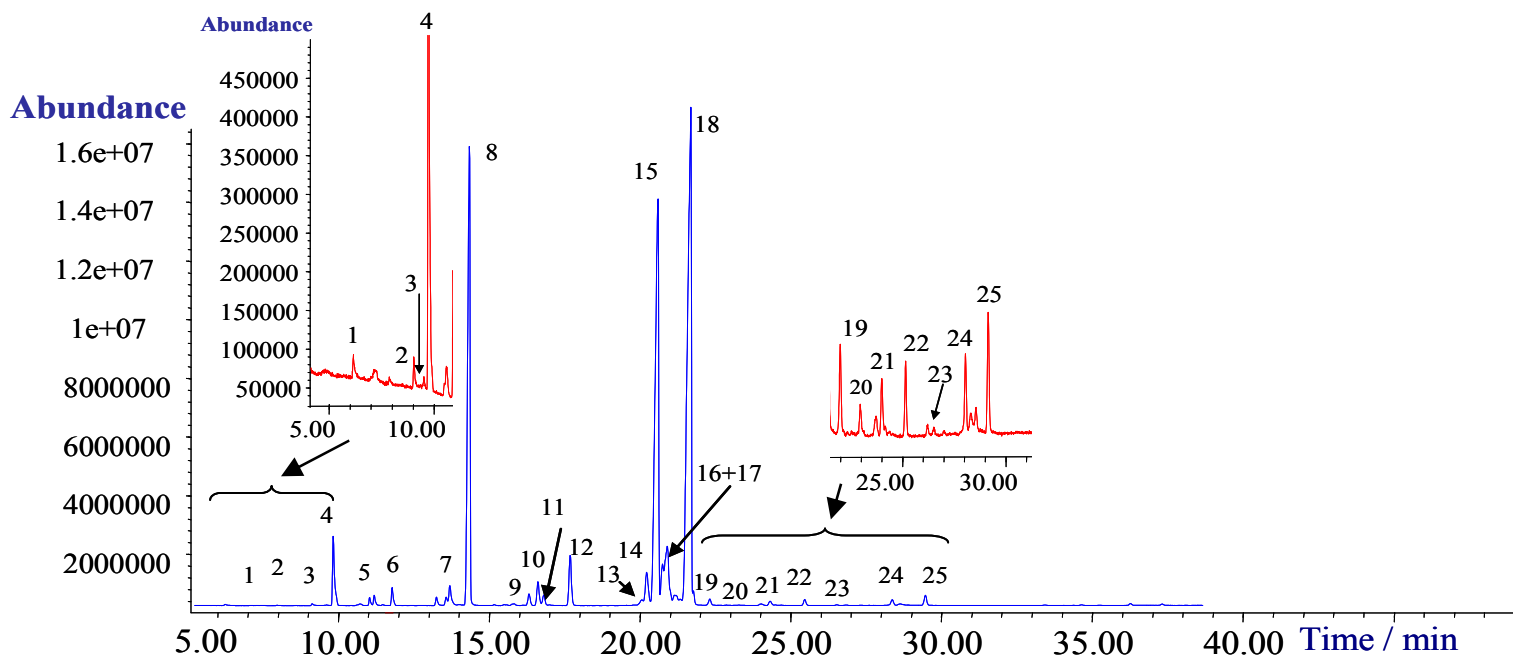

(B) Abundance

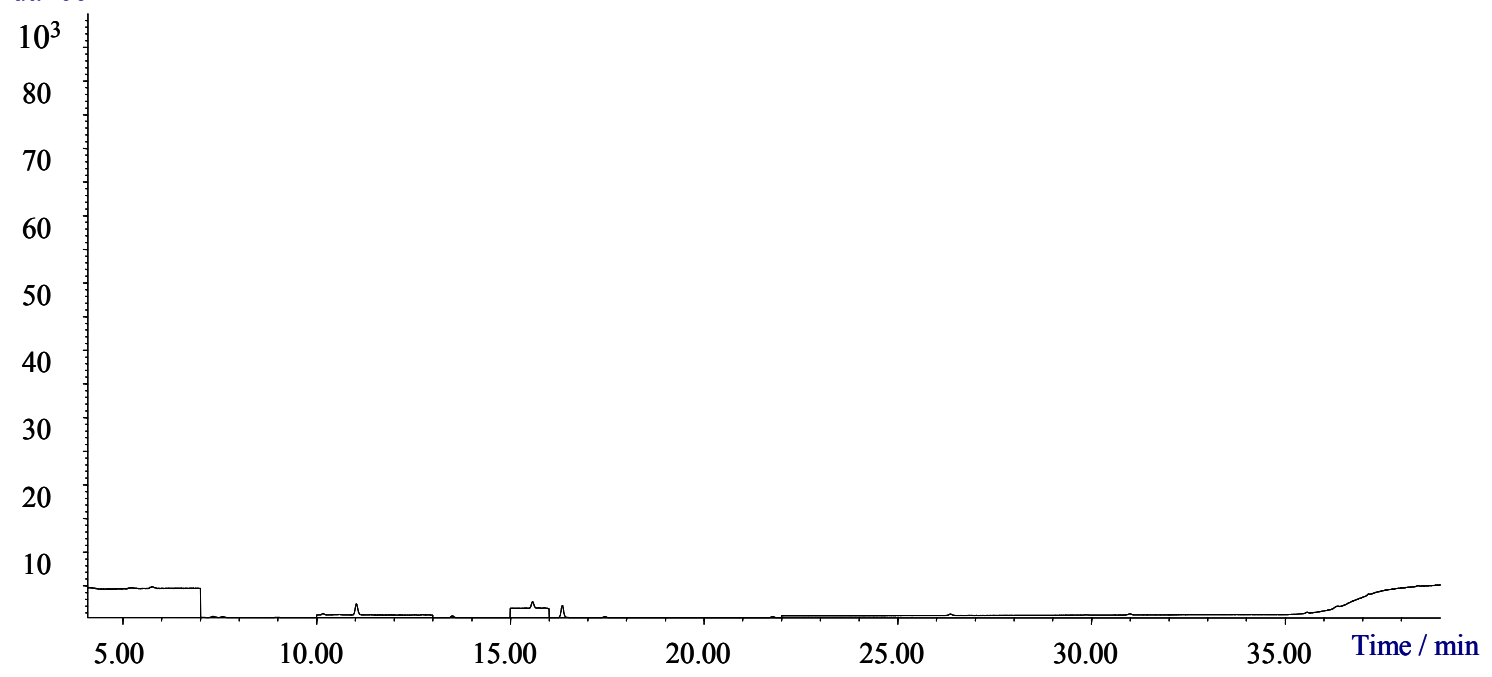

Figure 1. Cont. 

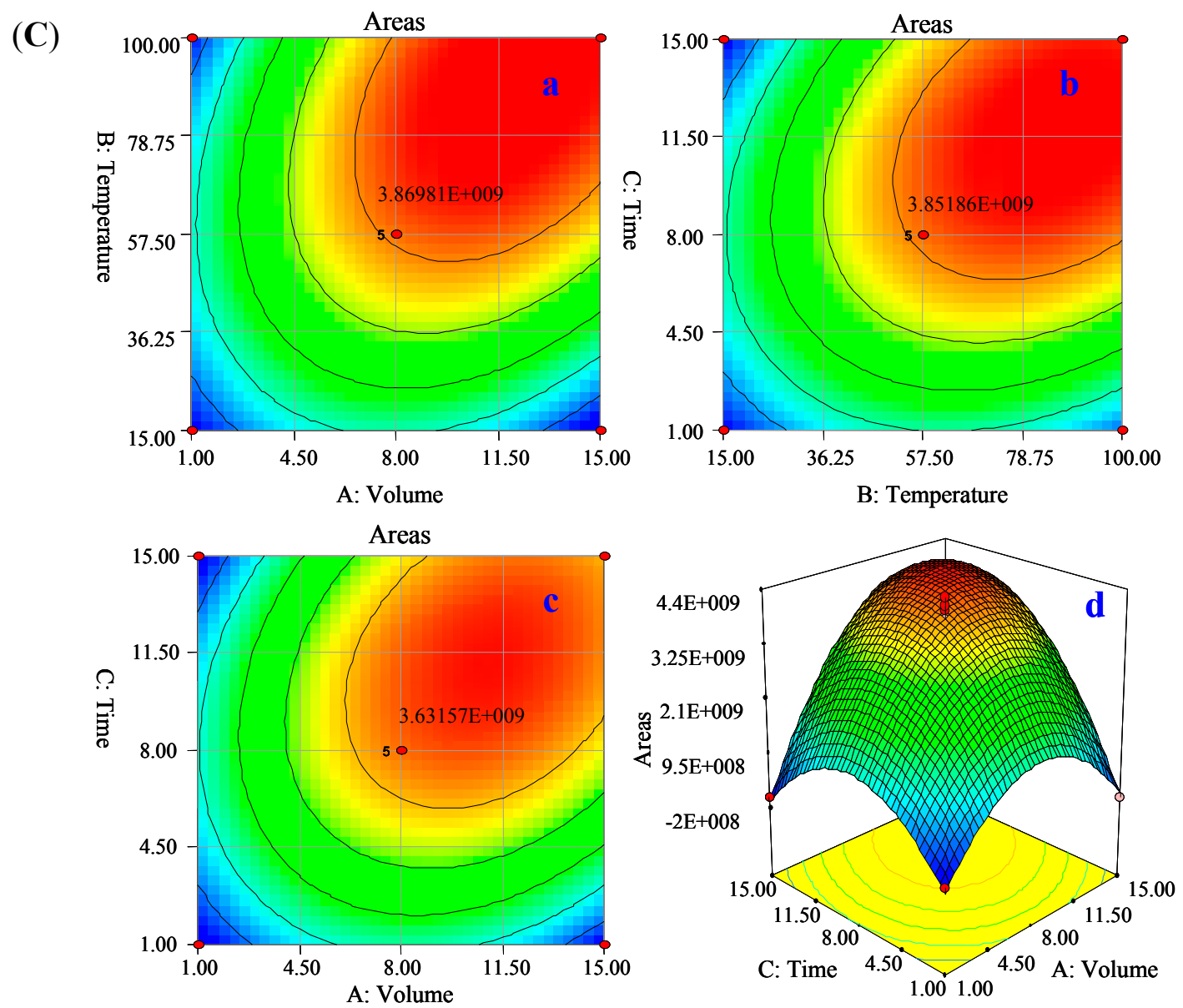

Figure 1. Optimization of precolumn methylesterified (PME) by Box-Behnken design (BBD)/GC-EI-qMS. (A) GC-EI-qMS chromatogram of the 25 fatty acid methyl esters (FAMEs) in suet oil (SO) sample under total ion chromatogram (TIC) mode. (1) Dodecanoic acid, methyl ester (DODME), (2) Methyl myristoleate, methyl ester, (3) Methyl 12-methyl-tridecanoate, methyl ester, (4) Tridecanoic acid, 12-methyl-, methyl ester, (5) Methyl tetradecanoate, methyl ester (MTEME), (6) Pentadecanoic acid, methyl ester (PENME), (7) (Z)-9-Hexadecenoic acid, methyl ester (9-HEME), (8) Hexadecanoic acid, methyl ester (HEXME), (9) Methyl 15-methylhexadecanoate, methyl ester, (10) cis-10-Heptadecenoic acid, methyl ester, (11) Heptadecanoic acid, methyl ester (HEPME), (12) (Z,Z)-9,12-Octadecadienoic acid, methyl ester (9,12-OCME), (13) Methyl 9-cis,11-trans-octadecadienoate methyl ester, (14) Methyl 10-trans,12-cis-octadecadienoate, (15) 9-Octadecenoic acid (E)-, methyl ester (9-OCME), (16) 9-Octadecenoic acid (Z)-, methyl ester, (17) 11-Octadecenoic acid, methyl ester, (18) Octadecanoic acid, methyl ester (OCTME), (19) cis-10-Nonadecenoic acid, methyl ester, (20) 10-Nonadecenoic acid, methyl ester, (21) Cyclopropaneoctanoic acid, 2-octyl-, methyl ester, (22) Nonadecanoic acid, methyl ester, (23) Methyl 8,11,14-eicosatrienoate, methyl ester, (24) cis-11-Eicosenoic acid, methyl ester, (25) Eicosanoic acid, methyl ester (EICME); (B) GC-EI-qMS chromatogram of representative blank samples under TIC mode; (C) Response surface plots (3-D) and contour (2-D) showing the total peaks areas with different methyl esterified condition. (a) 2-D panel of temperature-volum, (b) 2-D panel of time-temperature, (c) 2-D panel of time-volum, (d) 3-D response surface plots. 


\subsection{Fatty Acids (FAs) Composition in Suet Oil (SO)}

Identification of FAs was achieved by comparing molecular mass, ion fragments and abundance ratios in the NIST 08 spectral library. A typical total ion chromatogram obtained for SO samples is shown in Figure 1A.

The FAs in SO were investigated using optimized PME: $10 \mathrm{~mL}$ of $\mathrm{BF}_{3}-\mathrm{MeOH}(14 \%, v / v), 60{ }^{\circ} \mathrm{C}$ and $10 \mathrm{~min}$. The PME/GC-EI-qMS analysis of SO led to the identification of 25 different FAs (Table 1): including saturated FAs (dodecanoic acid, 12-methyl-tridecanoate, tridecanoic acid, 12-methyl-tetradecanoate, pentadecanoic acid, hexadecanoic acid, heptadecanoic acid, octadecanoic acid, cyclopropaneoctanoic acid, nonadecanoic acid, eicosanoic acid, cis-11-eicosenoic acid and 8,11,14-eicosatrienoate) and unsaturated FAs (myristoleate, 9-hexadecanoic acid, cis-10-heptadecanoic acid, (Z,Z)-9,12-octadecadienoic acid, 10-nonadecanoic acid, 10-trans,12-cis-octadecadienoate, (E)-9-octadecanoic acid, (Z)-9-octadecanoic acid, 11-octadecanoic acid, cis-10-nonadecanoic acid and 9-cis,11-trans-octadecadienoate).

In all, 25 FAs were identified (match $>90 \%$ ). Hexadecanoic acid, octadecanoic acid and (E)-9-octadecanoic acid were the three most abundant and occupied $16.46 \%, 37.96 \%$ and $19.47 \%$ of the total peak area, respectively (Table 1).

\subsection{Validation of Quantitative Analysis}

Methylester derivatives of the ten most abundant FAs were purchased for use as standards. These FAs in the SO samples were quantified by derivatization into FAMEs, which were analyzed by GC-EI-qMS without significant matrix interference. Four fragment ions were monitored in the SIM mode for each compound. The best characteristic ion in the spectrum was selected for quantification of each FAME and the other three were used for confirmation.

The validity of the method was investigated by examination of the linearity, recovery, and limit of quantification (LOQ) for all FAMEs in this study. The ranges of concentration, regression equations, $r^{2}$ (coefficient of determination), recovery, relative standard deviation (RSD) and LOQ for the target FAMEs are given in Table 2. Most of the FAMEs had good linearity $\left(r^{2}>0.999\right)$; more importantly, the results showed a stabilized recovery of ten FAMEs in the range $82.1 \%-98.7 \%$ with optimized PME parameters (Table 2, Figure S1) and the LOQ values of these FAMEs ranged from 1.25 to $5.95 \mu \mathrm{g} / \mathrm{L}$. These results indicated LOQ was sufficiently low to meet the requirements of determination of the FA composition of SOs. A chromatogram of these ten FAMEs in SOs obtained in the SIM mode is shown in Figure 2A. 
Table 1. Fatty acids identified in SO sample using precolumn esterified/GC-EI-qMS.

\begin{tabular}{|c|c|c|c|c|c|c|c|}
\hline No. & RT (min) & Compounds Name & CAS No. & $M \mathbf{w}^{\mathbf{a}}$ & Formula & Match (\%) & $\mathrm{RC}^{\mathrm{b}}(\%)$ \\
\hline 1 & 6.142 & Dodecanoic acid, methyl ester & 000111-82-0 & 214 & $\mathrm{C}_{13} \mathrm{H}_{26} \mathrm{O}_{2}$ & 98 & 0.11 \\
\hline 2 & 9.016 & Methyl myristoleate & 056219-06-8 & 240 & $\mathrm{C}_{15} \mathrm{H}_{28} \mathrm{O}_{2}$ & 96 & 0.19 \\
\hline 3 & 9.504 & Methyl 12-methyl-tridecanoate & $1000336-46-9$ & 242 & $\mathrm{C}_{15} \mathrm{H}_{30} \mathrm{O}_{2}$ & 98 & 0.087 \\
\hline 4 & 9.739 & Tridecanoic acid, 12-methyl-, methyl ester & $005129-58-8$ & 242 & $\mathrm{C}_{15} \mathrm{H}_{30} \mathrm{O}_{2}$ & 94 & 0.25 \\
\hline 5 & 11.071 & Methyl tetradecanoate & 000124-10-7 & 242 & $\mathrm{C}_{15} \mathrm{H}_{30} \mathrm{O}_{2}$ & 98 & 2.52 \\
\hline 6 & 11.663 & Pentadecanoic acid, methyl ester & $007132-64-1$ & 256 & $\mathrm{C}_{16} \mathrm{H}_{32} \mathrm{O}_{2}$ & 99 & 0.29 \\
\hline 7 & 13.614 & 9-Hexadecenoic acid, methyl ester, $(Z)$ - & 001120-25-8 & 268 & $\mathrm{C}_{17} \mathrm{H}_{32} \mathrm{O}_{2}$ & 99 & 2.51 \\
\hline 8 & 14.311 & Hexadecanoic acid, methyl ester & 000112-39-0 & 270 & $\mathrm{C}_{17} \mathrm{H}_{34} \mathrm{O}_{2}$ & 98 & 16.46 \\
\hline 9 & 16.253 & Methyl 15-methylhexadecanoate & $1000336-34-2$ & 284 & $\mathrm{C}_{18} \mathrm{H}_{36} \mathrm{O}_{2}$ & 99 & 0.64 \\
\hline 10 & 16.531 & cis-10-Heptadecenoic acid, methyl ester & $1000333-62-1$ & 282 & $\mathrm{C}_{18} \mathrm{H}_{34} \mathrm{O}_{2}$ & 99 & 0.98 \\
\hline 11 & 16.723 & Heptadecanoic acid, methyl ester & $001731-92-6$ & 284 & $\mathrm{C}_{18} \mathrm{H}_{36} \mathrm{O}_{2}$ & 99 & 1.06 \\
\hline 12 & 17.507 & 9,12-Octadecadienoic acid $(Z, Z)$-, methyl ester & 000112-63-0 & 294 & $\mathrm{C}_{19} \mathrm{H}_{34} \mathrm{O}_{2}$ & 99 & 1.61 \\
\hline 13 & 19.492 & Methyl 9-cis,11-trans-octadecadienoate & $1000336-44-0$ & 294 & $\mathrm{C}_{19} \mathrm{H}_{34} \mathrm{O}_{2}$ & 95 & 1.29 \\
\hline 14 & 19.919 & Methyl 10-trans,12-cis-octadecadienoate & $1000336-44-2$ & 294 & $\mathrm{C}_{19} \mathrm{H}_{34} \mathrm{O}_{2}$ & 96 & 0.10 \\
\hline 15 & 20.119 & 9-Octadecenoic acid $(E)$-, methyl ester & $001937-62-8$ & 296 & $\mathrm{C}_{19} \mathrm{H}_{36} \mathrm{O}_{2}$ & 99 & 37.96 \\
\hline 16 & 20.546 & 9-Octadecenoic acid (Z)-, methyl ester & 000112-62-9 & 296 & $\mathrm{C}_{19} \mathrm{H}_{36} \mathrm{O}_{2}$ & 99 & 1.97 \\
\hline 17 & 20.955 & 11-Octadecenoic acid, methyl ester & $052380-33-3$ & 296 & $\mathrm{C}_{19} \mathrm{H}_{36} \mathrm{O}_{2}$ & 99 & 2.05 \\
\hline 18 & 21.992 & Octadecanoic acid, methyl ester & 000112-61-8 & 298 & $\mathrm{C}_{19} \mathrm{H}_{38} \mathrm{O}_{2}$ & 99 & 19.47 \\
\hline 19 & 22.166 & cis-10-Nonadecenoic acid, methyl ester & $1000333-64-4$ & 310 & $\mathrm{C}_{20} \mathrm{H}_{38} \mathrm{O}_{2}$ & 98 & 0.065 \\
\hline 20 & 23.316 & 10-Nonadecenoic acid, methyl ester & $056599-83-8$ & 310 & $\mathrm{C}_{20} \mathrm{H}_{38} \mathrm{O}_{2}$ & 93 & 0.24 \\
\hline 21 & 24.308 & Cyclopropaneoctanoic acid, 2-octyl-, methyl ester & $3971-54-8$ & 310 & $\mathrm{C}_{20} \mathrm{H}_{38} \mathrm{O}_{2}$ & 99 & 0.42 \\
\hline 22 & 25.287 & Nonadecanoic acid, methyl ester & 001731-94-8 & 312 & $\mathrm{C}_{20} \mathrm{H}_{40} \mathrm{O}_{2}$ & 99 & 0.26 \\
\hline 23 & 26.829 & Methyl 8,11,14-eicosatrienoate & $1000336-38-1$ & 320 & $\mathrm{C}_{21} \mathrm{H}_{36} \mathrm{O}_{2}$ & 97 & 0.034 \\
\hline 24 & 28.262 & cis-11-Eicosenoic acid, methyl ester & $1000333-63-8$ & 324 & $\mathrm{C}_{21} \mathrm{H}_{40} \mathrm{O}_{2}$ & 99 & 0.12 \\
\hline 25 & 29.653 & Eicosanoic acid, methyl ester & 001120-28-1 & 326 & $\mathrm{C}_{21} \mathrm{H}_{42} \mathrm{O}_{2}$ & 99 & 0.20 \\
\hline
\end{tabular}

${ }^{\mathrm{a}} \mathrm{M} \mathrm{w}=$ Molecular Weight (nominal values); ${ }^{\mathrm{b}} \mathrm{RC}(\%)=$ The relative content of total peak areas, the sum of the RC was $90.89 \%$, the other $9.11 \%$ may contain inorganic elements, glycerin and something else. 
Table 2. The linear regression equations, the correlation coefficient (r), limit of quantification (LOQ), recoveries of 10 fatty acids under GC-EI-qMS selective ion monitoring (SIM) conditions.

\begin{tabular}{|c|c|c|c|c|c|c|c|c|c|c|c|c|c|}
\hline \multirow{2}{*}{$\begin{array}{c}\text { NO. of } \\
\text { Identified } \\
\text { Fatty Acids }\end{array}$} & \multirow{2}{*}{ Compounds } & \multirow{2}{*}{$\begin{array}{c}\text { Linear } \\
\text { Regression } \\
\text { Equations }\end{array}$} & \multirow{2}{*}{$\begin{array}{c}\text { Coefficient of } \\
\text { Determination } / r^{2}\end{array}$} & \multirow{2}{*}{$\begin{array}{c}\text { Linear } \\
\text { Range } \\
\mu \mathrm{g} / \mathrm{mL}\end{array}$} & \multirow{2}{*}{$\begin{array}{c}\text { Qualitative/ } \\
\text { Quantitative Ions }\end{array}$} & \multirow{2}{*}{$\begin{array}{l}\text { Abundance } \\
\text { Ratio (\%) }\end{array}$} & \multicolumn{2}{|c|}{$\begin{array}{c}\text { 0.5 Times Spiked } \\
(n=3) \\
\end{array}$} & \multicolumn{2}{|c|}{$\begin{array}{c}1.0 \text { Times Spiked } \\
(n=3) \\
\end{array}$} & \multicolumn{2}{|c|}{$\begin{array}{c}2.0 \text { Times Spiked } \\
(n=3)\end{array}$} & \multirow{2}{*}{$\begin{array}{r}\text { LOQ } \\
(\mu \mathrm{g} / \mathrm{mL} \\
\left.\times 10^{-3}\right)\end{array}$} \\
\hline & & & & & & & $\begin{array}{c}\text { Recovery } \\
(\%) \\
\end{array}$ & $\begin{array}{c}\text { RSDs } \\
(\%) \\
\end{array}$ & $\begin{array}{c}\text { Recovery } \\
(\%) \\
\end{array}$ & $\begin{array}{c}\text { RSDs } \\
(\%)\end{array}$ & $\begin{array}{c}\text { Recovery } \\
(\%) \\
\end{array}$ & $\begin{array}{c}\text { RSDs } \\
(\%) \\
\end{array}$ & \\
\hline 1 & DODME & $\begin{aligned} Y & =1.56 \times 10^{4} X \\
& -1.79 \times 10^{3}\end{aligned}$ & 0.999 & $0.010-10.0$ & $74 *: 28: 87: 214$ & $100: 8: 64: 6$ & 85.3 & 4.3 & 92.4 & 4.8 & 93.2 & 2.2 & 1.25 \\
\hline 5 & MTEME & $\begin{aligned} Y & =1.54 \times 10^{4} X \\
& -1.48 \times 10^{3}\end{aligned}$ & 0.999 & $0.013-12.8$ & $74 *: 87: 143: 199$ & $100: 68: 24: 16$ & 95.2 & 4.1 & 97.2 & 3.3 & 98.7 & 4.5 & 1.60 \\
\hline 6 & PENME & $\begin{aligned} Y & =1.86 \times 10^{4} \mathrm{X} \\
& -4.74 \times 10^{3}\end{aligned}$ & 0.999 & $0.011-12.0$ & $74 *: 87: 143: 213$ & $100: 68: 20: 18$ & 91.3 & 6.2 & 92.8 & 4.5 & 95.8 & 4.2 & 1.40 \\
\hline 7 & 9-HEXME & $\begin{aligned} Y & =3.10 \times 10^{3} X \\
& -1.13 \times 10^{3}\end{aligned}$ & 0.999 & $0.020-20.0$ & $55 *: 74: 87: 236$ & $100: 68: 50: 23$ & 83.6 & 4.8 & 94.6 & 3.5 & 96.6 & 2.4 & 2.50 \\
\hline 8 & HEXME & $\begin{array}{c}Y=2.62 \times 10^{4} X \\
-1.579 \times 10^{4}\end{array}$ & 0.999 & $0.048-50.0$ & $74 *: 87: 143: 227$ & $100: 70: 20: 14$ & 87.5 & 5.2 & 95.4 & 5.4 & 96.9 & 3.8 & 5.95 \\
\hline 11 & HEPME & $\begin{aligned} Y & =2.93 \times 10^{4} X \\
& -6.54 \times 10^{3}\end{aligned}$ & 0.999 & $0.013-13.0$ & $74 *: 87: 143: 241$ & $100: 70: 22: 15$ & 87.6 & 6.8 & 90.8 & 5.0 & 92.7 & 4.1 & 1.63 \\
\hline 12 & 9,12-OCME & $\begin{aligned} Y & =7.71 \times 10^{3} X \\
& -1.15 \times 10^{2}\end{aligned}$ & 0.999 & $0.020-20.0$ & $67 *: 81: 95: 294$ & 100:92:66:16 & 91.7 & 4.4 & 91.7 & 2.8 & 93.9 & 3.6 & 2.50 \\
\hline 15 & 9-OCME & $\begin{aligned} Y & =5.02 \times 10^{3} X \\
& -3.62 \times 10^{2}\end{aligned}$ & 0.999 & $0.020-20.0$ & $55 *: 41: 81: 222$ & $100: 62: 40: 24$ & 84.8 & 5.1 & 88.4 & 4.2 & 97.2 & 4.4 & 2.50 \\
\hline 18 & OCTME & $\begin{aligned} Y & =3.31 \times 10^{4} X \\
& -1.24 \times 10^{4}\end{aligned}$ & 0.999 & $0.030-32.0$ & $74 *: 87: 143: 255$ & $100: 72: 23: 14$ & 85.5 & 4.3 & 86.7 & 5.2 & 88.8 & 5.1 & 3.75 \\
\hline 25 & EICME & $\begin{array}{c}Y=3.18 \times 10^{4} X \\
-4.78 \times 10^{3}\end{array}$ & 0.999 & $0.010-10.8$ & $74 *: 87: 143: 255$ & $100: 76: 26: 18$ & 82.1 & 3.9 & 90.1 & 4.7 & 89.4 & 3.7 & 1.25 \\
\hline
\end{tabular}

* Quantitative ion, LOQ was calculated as 10 times of the signal to noise ratio (10 S/N). 0.5, 1.0 and 2.0 times "Spiked" means the added standards amount was 0.5 , 1.0 and 2.0 times of the initial content of samples. 
(A)
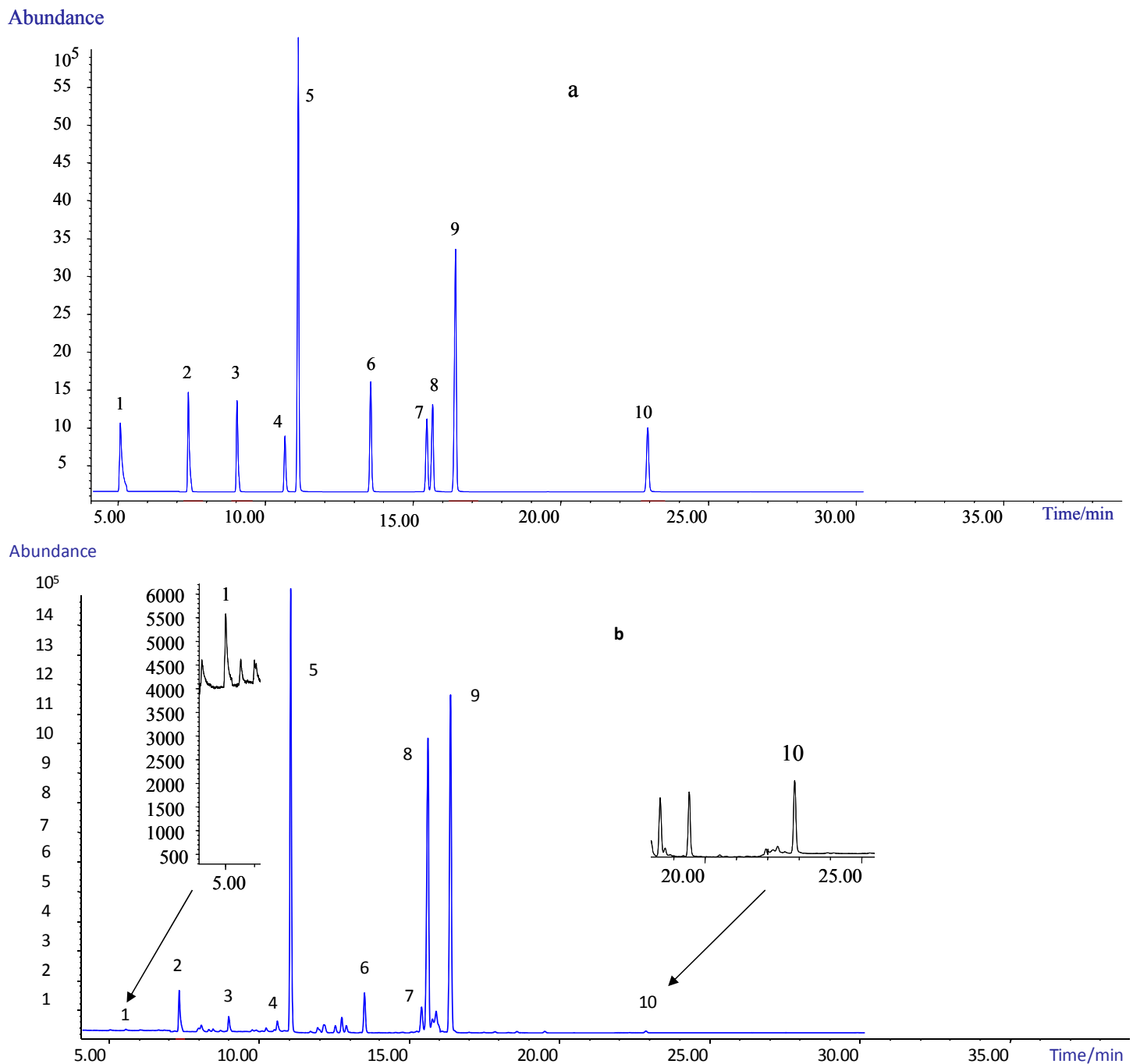

(B)

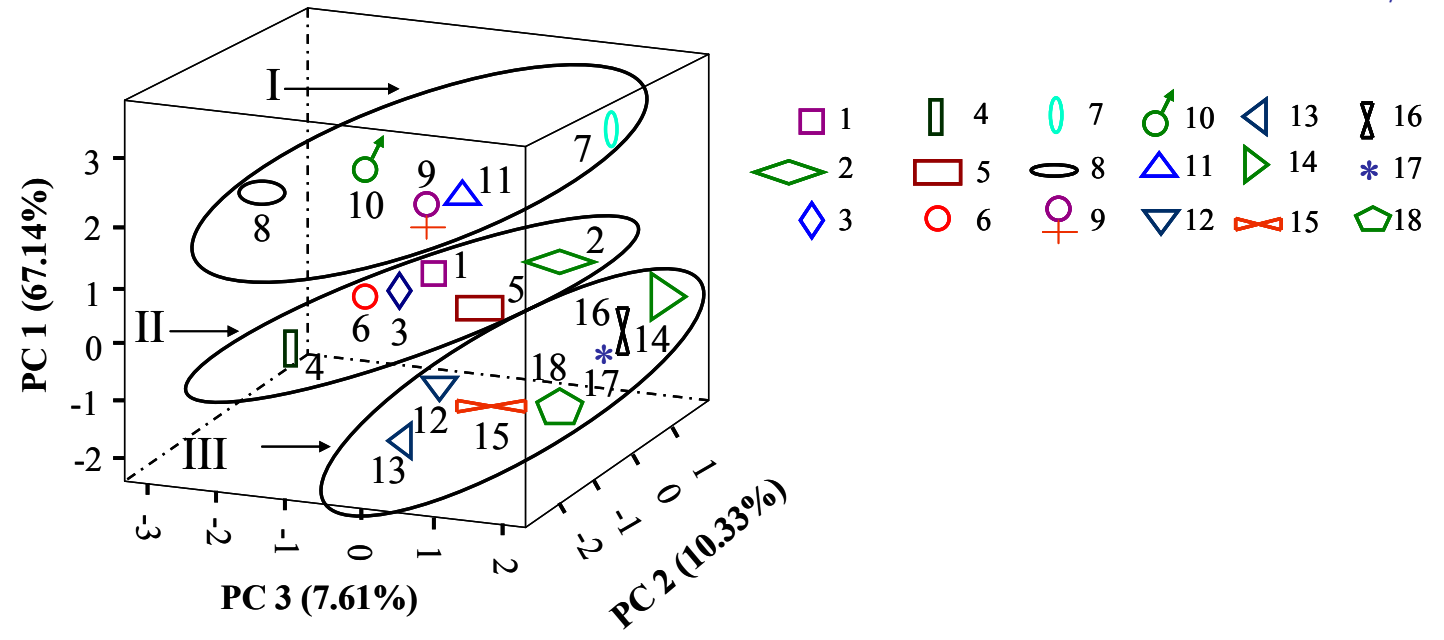

Figure 2. GC-EI-qMS chromatograms of the ten FAMEs standard mixture and sample under SIM mode and principal component analysis (PCA) of 18 SO samples. (A) (a) mixed standard solution (the concentration of (1-10) was 10.8, 47.6, 31.6, 13.0, 11.2, 12.8, 10.0, 20.0, 20.0 and $20.0 \mu \mathrm{g} / \mathrm{mL}$, respectively), (b) SO sample solution. (1) DODME, (2) MTEME, (3) PENME, (4) 9-HEXME, (5) HEXME, (6) HEPME, (7) 9,12-OCME, (8) 9-OCME, (9) OCTME, (10) EICME; (B) The 3D scatter plot obtained by PCA of 18 SO samples. 


\subsection{Quantitative Results}

The molecular species detected after methylesterification were FAMEs rather than FAs. Therefore, in order to quantify the FAs, the contents of FAMEs were converted into FAs by multiplication with the corresponding coefficient as follows:

$$
W_{\mathrm{FAs}}(\%)=A \times W_{\mathrm{FAMEs}}(\%)
$$

where $W$ is concentration and $A$ is the molecular mass of the FAMEs/the molecular mass of the FAs.

The results for ten FAs in 18 batches of SO are given in Table 3. The contents of hexadecanoic acid and octadecanoic acid were $3.79 \%-13.22 \%$ and $3.41 \%-18.11 \%$, respectively. The contents of (E)-9-octadecanoic acid in SO batches 3-6, 8, 12-15 and 18 were $4.48 \%-6.28 \%$, second only to hexadecanoic acid and octadecanoic acid, whereas no other FA was detected. On the basis of the quantitative results for 18 batches of SO, the content of octadecanoic acid was greatest, followed by hexadecanoic acid, $(E)$-9-octadecanoic acid and tetradecanoate in that order.

\subsection{Principal Component Analysis (PCA) of the SO Samples}

In order to evaluate the variation between batches of SO, PCA was applied on the basis of the contents of the ten most abundant FAs. The first three principal components (PC1, PC2 and PC3) with $>85 \%$ of the whole variance were extracted for analysis. PC1, PC2 and PC3 accounted for 67.14\%, $10.33 \%$ and $7.61 \%$ of the total variance, respectively (Table S1). The remaining principal components had only a minor effect on the model and were discarded. The component loading matrix is given in Table S2 and S3. According to the loadings, PC1 had a good correlation with each of the ten FA compounds. The results mentioned above suggested that most of the compounds contributed to the classification of the samples. The scatter plots are shown in Figure 2B, where each sample is represented as one marker.

The dots of 18 samples were classified into group I, group II or group III in accord with their origin. Dots in groups II and III were relatively close to each other, indicating a close relationship among the six batches from Anhui and the seven batches from Jiangsu. The dots in group I were quite scattered, suggesting diversification of the five batches from Qinghai Province. These observations might be explained as follows. Firstly, the land area of Qinghai Province $\left(722,300 \mathrm{~km}^{2}\right)$ is larger compared to Anhui Province $\left(1,396,002 \mathrm{~km}^{2}\right)$ and Jiangsu Province $\left(106,700 \mathrm{~km}^{2}\right)$, representing a greater area for diversity of the samples. Secondly, Qinghai, Anhui and Jiangsu provinces are considerably different environments with large differences in climate, which influences the differences in FA metabolism in domestic sheep and goats. Thirdly, Anhui and Jiangsu provinces are geographic neighbors, which is reflected in the similarities among samples from these two origins. Finally, the SO samples from Qinghai Province were from sheep, whereas those obtained from Anhui and Jiangsu provinces were from goats. 
Table 3. Contents of ten FAs in 18 batches of Suet oil $(n=3)$.

\begin{tabular}{|c|c|c|c|c|c|c|c|c|c|c|}
\hline FAs Compounds & DODME & MTEME & PENME & 9-HEXME & HEXME & HEPME & 9,12-ОСМЕ & 9-ОСМЕ & OCTME & EICME \\
\hline Coefficient "A & 348 & 9414 & 9454 & 0.9478 & 0.9482 & 0.9508 & 0.9524 & 0.9527 & 0.9531 & 0.9571 \\
\hline Batch & \multicolumn{10}{|c|}{ Content $(g / 100 \mathrm{~g}, \%)^{\mathrm{b}}$} \\
\hline 1 & $0.0240 \pm 0.0014$ & $1.1476 \pm 0.0014$ & $0.2124 \pm 0.0002$ & $0.5716 \pm 0.0012$ & $8.9067 \pm 0.1483$ & $0.4996 \pm 0.0006$ & $0.8667 \pm 0.0015$ & $\mathrm{Nd}$ & $12.5609 \pm 0.1614$ & $0.0933 \pm 0.0021$ \\
\hline 2 & $0.0284 \pm 0.0010$ & $1.0827 \pm 0.0012$ & $0.1787 \pm 0.0015$ & $0.4596 \pm 0.0029$ & $7.6098 \pm 0.0040$ & $0.5022 \pm 0.0011$ & $1.1867 \pm 0.0023$ & $\mathrm{Nd}$ & $11.0827 \pm 0.0011$ & $0.1040 \pm 0.0023$ \\
\hline 3 & $0.0284 \pm 0.0009$ & $0.8684 \pm 0.0010$ & $0.2009 \pm 0.0028$ & $0.4044 \pm 0.0025$ & $6.2578 \pm 0.0157$ & $0.5289 \pm 0.0053$ & $1.1218 \pm 0.0102$ & $\mathrm{Nd}$ & $8.7600 \pm 0.3606$ & $0.0942 \pm 0.0013$ \\
\hline 4 & $0.0196 \pm 0.0004$ & $0.4862 \pm 0.0015$ & $0.2098 \pm 0.0039$ & $0.4204 \pm 0.0023$ & $4.4382 \pm 0.0011$ & $0.4551 \pm 0.0022$ & $0.6587 \pm 0.0065$ & $\mathrm{Nd}$ & $4.0124 \pm 0.0017$ & $0.0471 \pm 0.0008$ \\
\hline 5 & $0.0231 \pm 0.0023$ & $0.7707 \pm 0.0083$ & $0.1991 \pm 0.0017$ & $0.3191 \pm 0.0017$ & $5.8071 \pm 0.0045$ & $0.5707 \pm 0.0015$ & $0.6604 \pm 0.0024$ & $4.5991 \pm 0.0053$ & $10.2213 \pm 0.0163$ & $0.1467 \pm 0.0032$ \\
\hline 6 & $0.0418 \pm 0.0012$ & $1.1912 \pm 0.0034$ & $0.2844 \pm 0.0012$ & $1.3378 \pm 0.0051$ & $7.5067 \pm 0.0074$ & $0.6187 \pm 0.0052$ & $0.9227 \pm 0.0008$ & $\mathrm{Nd}$ & $8.3093 \pm 0.0297$ & $0.0978 \pm 0.0017$ \\
\hline 7 & $0.0400 \pm 0.0031$ & $1.9422 \pm 0.0068$ & $0.3040 \pm 0.0108$ & $1.1564 \pm 0.0020$ & $13.2151 \pm 0.0241$ & $0.7956 \pm 0.0023$ & $1.4640 \pm 0.0028$ & $\mathrm{Nd}$ & $18.1129 \pm 0.0028$ & $0.1662 \pm 0.0035$ \\
\hline 8 & $0.0328 \pm 0.0017$ & $1.1182 \pm 0.0037$ & $0.2729 \pm 0.0017$ & $0.7662 \pm 0.0026$ & $7.9458 \pm 0.0026$ & $0.7218 \pm 0.0017$ & $0.9048 \pm 0.0033$ & $\mathrm{Nd}$ & $12.1111 \pm 0.0015$ & $0.1582 \pm 0.0001$ \\
\hline 9 & $0.0400 \pm 0.0031$ & $1.4516 \pm 0.0012$ & $0.3902 \pm 0.0035$ & $0.8649 \pm 0.0033$ & $10.8133 \pm 0.0034$ & $1.1004 \pm 0.0001$ & $1.4924 \pm 0.0035$ & $\mathrm{Nd}$ & $12.9360 \pm 0.0275$ & $0.1111 \pm 0.0016$ \\
\hline 10 & $0.0280 \pm 0.0046$ & $1.0978 \pm 0.0045$ & $0.2516 \pm 0.0024$ & $0.4222 \pm 0.0029$ & $8.264 \pm 0.0394$ & $0.6960 \pm 0.0027$ & $1.0480 \pm 0.0042$ & $\mathrm{Nd}$ & $13.0320 \pm 0.0337$ & $0.1467 \pm 0.0040$ \\
\hline 11 & $0.0373 \pm 0.0035$ & $1.1991 \pm 0.0031$ & $0.4791 \pm 0.0033$ & $0.4764 \pm 0.0040$ & $10.0676 \pm 0.0045$ & $0.9218 \pm 0.0017$ & $0.8107 \pm 0.0059$ & $\mathrm{Nd}$ & $14.2569 \pm 0.0029$ & $0.1040 \pm 0.0016$ \\
\hline 12 & $0.0356 \pm 0.0039$ & $1.0196 \pm 0.0041$ & $0.2658 \pm 0.0039$ & $0.7564 \pm 0.0031$ & $6.7449 \pm 0.0017$ & $0.4942 \pm 0.0033$ & $0.7787 \pm 0.0041$ & $6.2764 \pm 0.0023$ & $6.0773 \pm 0.0036$ & $0.0560 \pm 0.0034$ \\
\hline 13 & $0.0178 \pm 0.0040$ & $0.4080 \pm 0.0046$ & $0.1769 \pm 0.0034$ & $0.3396 \pm 0.0044$ & $3.7902 \pm 0.0047$ & $0.3804 \pm 0.0018$ & $0.5449 \pm 0.0039$ & $5.4489 \pm 0.0048$ & $3.4080 \pm 0.0051$ & $0.0382 \pm 0.0012$ \\
\hline 14 & $0.0322 \pm 0.0035$ & $1.1831 \pm 0.0040$ & $0.2391 \pm 0.0045$ & $0.4276 \pm 0.0046$ & $8.3760 \pm 0.0164$ & $0.5822 \pm 0.0029$ & $1.2240 \pm 0.0167$ & $5.2880 \pm 0.0282$ & $11.2276 \pm 0.0060$ & $0.087 \pm 0.0045$ \\
\hline 15 & $0.0240 \pm 0.0023$ & $0.6462 \pm 0.0034$ & $0.1458 \pm 0.0028$ & $0.4587 \pm 0.0013$ & $4.6827 \pm 0.0034$ & $0.3671 \pm 0.0035$ & $0.6240 \pm 0.0293$ & $5.0649 \pm 0.0034$ & $6.6560 \pm 0.0220$ & $0.0773 \pm 0.0038$ \\
\hline 16 & $0.0267 \pm 0.0029$ & $0.8071 \pm 0.0039$ & $0.1636 \pm 0.0032$ & $0.3363 \pm 0.0032$ & $5.8738 \pm 0.0015$ & $0.4747 \pm 0.0038$ & $1.0738 \pm 0.0028$ & $4.8996 \pm 0.0044$ & $9.0898 \pm 0.0042$ & $0.0969 \pm 0.0023$ \\
\hline 17 & $0.0267 \pm 0.0034$ & $0.7911 \pm 0.0061$ & $0.1564 \pm 0.0028$ & $0.3209 \pm 0.0078$ & $5.4720 \pm 0.0406$ & $0.4329 \pm 0.0030$ & $1.0169 \pm 0.0033$ & $4.6578 \pm 0.0046$ & $8.1529 \pm 0.0040$ & $0.0862 \pm 0.0039$ \\
\hline 18 & $0.0160 \pm 0.0051$ & $0.6969 \pm 0.0034$ & $0.0907 \pm 0.0064$ & $0.3413 \pm 0.0031$ & $5.5209 \pm 0.0071$ & $0.2480 \pm 0.0046$ & $0.5013 \pm 0.0034$ & $4.4756 \pm 0.0034$ & $7.9644 \pm 0.0033$ & $0.0622 \pm 0.0042$ \\
\hline
\end{tabular}

${ }^{\mathrm{a}} \mathrm{A}=$ Molecular Weight $_{(\mathrm{FAMEs})} /$ Molecular Weight $_{(\mathrm{FAs})}$; ${ }^{\mathrm{b}} \mathrm{W}_{\mathrm{FAs}}(\%)=\mathrm{A} \times \mathrm{W}_{\mathrm{FAMEs}}(\%) ; \mathrm{Nd}=$ not detected. 


\section{Experimental Section}

\subsection{Materials}

Methyl dodecanoic acid (DODME $\geq 98.0$ (purity)), methyl tetradecanoate (MTEME $\geq 99.0$ ), methyl pentadecanoic acid (PENME $\geq$ 98.0), methyl 9-hexadecenoic acid $(Z)$ (9-HEME $\geq$ 99.0), methyl hexadecanoic acid (HEXME $\geq 99.0$ ), methyl heptadecanoic acid (HEPME $\geq 99.0$ ), 9,12-methyl octadecadienoic acid $(Z, Z)(9,12-O C M E \geq 99.0)$, methyl 9-octadecenoic acid $(E)$ (9-OCME $\geq 99.0)$, methyl octadecanoic acid (OCTME $\geq 98.0$ ), methyl eicosanoic acid (EICME $\geq 99.0$ ), boron trifluoride-methanol $(14 \%, v / v)$, sodium hydroxide $(\mathrm{NaOH})$ and sodium $(\mathrm{NaCl})$ were purchased from Anpel Scientific Instrument Co., Ltd. (Shanghai, China). HPLC grade methanol, and $n$-hexane were obtained from Merck (Darmstadt, Germany).

\subsection{Sample Material}

Eighteen batches of SO samples were purchased from Qinghai (batches 7-11), Jiangsu (batches 12-18) and Anhui (batches 1-6) provinces, China between January and July 2013 (Figure S2). All samples were stored in darkness at temperatures $<4{ }^{\circ} \mathrm{C}$. For the blank sample, the $n$-hexane was used instead of SOs.

\subsection{Box-Behnken Design for Optimization of PME Parameters}

The application of an effective PME methodology requires optimization of the main parameters that influence the methylesterification process, including the volume of methyl reagent, temperature and time.

A Box-Behnken Design, a response surface methodology, was used in this study. Design Expert 7.0.0 software was used for analyzing the experimental data. The study type was Response Surface, the initial design was Box-Behnken, the design model was Quadratic and Blocks was No Blocks. A Box-Behnken statistical screening design with three independent variables ( $A$, PME volume; $B$, PME temperature; $C$, PME time) was used to optimize the PME process for the qualitative and quantitative analysis. Statistically significant difference was set at $p \leq 0.05$. The $r^{2}$ value of the "Final Equation" $>0.995$ indicated derived results were accurate. Data were expressed as mean \pm standard deviation (SD) of triplicate determinations. Statistical calculations used Statistical Product and Service Solutions (SPSS) version 16.0 software (SPSS Inc., Chicago, IL, USA). One-way ANOVA was used for evaluating the statistical differences among samples.

\subsection{PME Procedure}

A $0.4 \mathrm{~g}$ sample of SO from batch 12 was weighed and placed into a $50-\mathrm{mL}$ conical flask followed by $15 \mathrm{~mL} \mathrm{NaOH}-\mathrm{MeOH}(0.5 \mathrm{~mol} / \mathrm{L})$ then heated at $60{ }^{\circ} \mathrm{C}$ in a waterbath for $20 \mathrm{~min}$ until the yellow beads of SO disappeared completely after cooling. The flask contents were subjected to the PME procedure, in which $10 \mathrm{~mL}$ of boron trifluoride methanol $\left(\mathrm{BF}_{3}-\mathrm{MEOH}, 14 \% v / v\right)$ was added to the flask then heated at $60{ }^{\circ} \mathrm{C}$ in a waterbath for $10 \mathrm{~min}$. The mixture was cooled and then $10 \mathrm{~mL}$ of $n$-hexane and $10 \mathrm{~mL}$ of saturated $\mathrm{NaCl}$ were added. Samples $1.5 \mathrm{~mL}$ of supernatants were injected through a $0.45-\mu \mathrm{m}$ pore size membrane before GC-EI-qMS qualitative analysis. 


\subsection{Sample Pretreatment for Quantitative Analysis}

Eighteen batches of SO were treated as described in section 3.4 above. Sequentially, $25-\mu \mathrm{L}$ was transferred into a $10-\mathrm{mL}$ volumetric flask followed by addition of $n$-hexane to a final volume of $10 \mathrm{~mL}$ and then shaken. After passage through an organic $0.45-\mu \mathrm{m}$ pore size filter, the treated samples were injected into the GC-EI-qMS for quantitative analysis.

\subsection{Preparation of Standard Solutions}

Stock solutions of the ten FAMEs (DODME, MTEME, PENME, 9-HEXME, HEXME, HEPME, 9,12-OCME, EICME, OCTME and 9-OCME) were prepared in $n$-hexane at concentrations of 20.0, $11.2,20.0,12.8,31.6,47.6,10.8,20.0,13.0$ and $10.0 \mu \mathrm{g} / \mathrm{mL}$, respectively. Appropriate amounts of the above stock solutions were mixed and diluted into a series of concentrations with $n$-hexane to obtain the working solutions. All solutions were stored at $<4{ }^{\circ} \mathrm{C}$.

\subsection{GC-EI-qMS Analysis Conditions}

For separation, detection and identification of FAs, the qualitative and quantitative analyses were made with a GC-EI-qMS instrument (Agilent 7890/5975) coupled to an automatic sampler (Agilent 7693) and an electron impact ionization source (Agilent, Santa Clara, CA, USA). Water was purified by a Milli-Q Plus apparatus (Millipore, Bedford, MA, USA). The H2050R centrifugal apparatus was provided by the Hunan Saite xiangyi centrifuge instrument Co., Ltd. (Xiangya, China).

Analytes were separated using a $30 \mathrm{~m} \times 0.25 \mathrm{~mm}$ capillary column (HP-5 ms $0.25 \mu \mathrm{m}$ film thickness; Agilent Technology, Santa Clara, CA, USA). The primary oven temperature protocol was: $150{ }^{\circ} \mathrm{C}$ for $1 \mathrm{~min}$; increased to $200^{\circ} \mathrm{C}$ at $5{ }^{\circ} \mathrm{C} / \mathrm{min}$; maintained at this temperature for $5 \mathrm{~min}$; increased to $250{ }^{\circ} \mathrm{C}$ at a rate of $5{ }^{\circ} \mathrm{C} / \mathrm{min}$; maintained at this temperature for $5 \mathrm{~min}$; increased to $300{ }^{\circ} \mathrm{C}$ at a rate of $5{ }^{\circ} \mathrm{C} / \mathrm{min}$; and maintained at this temperature for $10 \mathrm{~min}$. The injection port temperature was $250{ }^{\circ} \mathrm{C}$. The carrier gas was helium at a constant flow of $1 \mathrm{~mL} / \mathrm{min}$. The MS operating conditions in the splitless injection mode were as follows: ion source temperature $280{ }^{\circ} \mathrm{C}$; electron energy $70 \mathrm{eV}$; emission current $250 \mu \mathrm{A}$; injection volume $0.2 \mu \mathrm{L}$; and solvent delay $4 \mathrm{~min}$. The SIM mode was used for quantitative determination of FAs.

\subsection{Method for PCA of Samples}

PCA was done with SPSS 16.0 software (SPSS, Chicago, IL, USA) [29]. In this study, the contents of the ten FAs in the $18 \mathrm{SO}$ samples were used as a data matrix with 18 rows and ten columns for PCA analysis after normalization. The first three PCs were extracted, and the scatter plot was obtained by plotting the scores of PC1 vs. PC2 and PC3.

\section{Conclusions}

The optimal conditions for methylesterification of FAs were obtained by a Box-Behnken Design, which identified 25 kinds of FAs in SO by GC-EI-qMS. In addition, ten FAs in 18 batches of SO were analyzed with good performance with regard to selectivity, recovery, precision and accuracy. 
Significant differences among origins in FA composition profiles and their contents were revealed. The method described here could be used in quality control and standardization of SOs and their products as well as providing supportive chemical information.

\section{Supplementary Materials}

Supplementary materials can be found at http://www.mdpi.com/1422-0067/16/02/2864/s1.

\section{Acknowledgments}

This work was supported by the Natural Science Foundation of China (No. 81274088).

\section{Author Contributions}

Jun Jiang designed research; Jun Jiang and Xiaobin Jia performed research and analyzed the data; Jun Jiang wrote the paper. Both authors read and approved the final manuscript.

\section{Conflicts of Interest}

The authors declare no conflict of interest.

\section{References}

1. Thurnhofer, S.; Hottinger, G.; Vetter, W. Enantioselective determination of anteiso fatty acids in food samples. Anal. Chem. 2007, 79, 4696-4701.

2. Mattacks, C.A.; Sadler, D.; Pond, C.M. Site-specific differences in the action of NRTI drugs on adipose tissue incubated in vitro with lymphoid cells, and their interaction with dietary lipids. Comp. Biochem. Phys. 2003, 135, 11-29.

3. Thurnhofer, S.; Vetter, W. A gas chromatography/electron ionization-mass spectrometry-selected ion monitoring method for determining the fatty acid pattern in food after formation of fatty acid methyl esters. J. Agric. Food Chem. 2005, 53, 8896-8903.

4. Barzanti, V.; Maranesi, M.; Cornia, G.L.; Malavolti, M.; Mordenti, T.; Pregnolato, P. Effect of dietary oils containing different amounts of precursor and derivative fatty acids on prostaglandin E2 synthesis in liver, kidney and lung of rats. Prostag. Leukotr. Essent. 1999, 60, 49-54.

5. Cui, L.; Sun, E.; Zhang, Z.H.; Tan, X.B.; Wei, Y.J.; Jin, X. Enhancement of epimedium fried with suet oil based on in vivo formation of self-assembled flavonoid compound nanomicelles. Molecules 2012, 17, 12984-12996.

6. Ansorena, D.; Raes, K.; de Smet, S.; Demeyer, D. Analysis of fatty acid isomers in ruminant tissues by silver thin layer chromatography followed by gas chromatography. Meded. Rijksuniv. Gent Fak. Landbouwkd. Toegep. Biol. Wet. 2001, 66, 365-372.

7. Zhang, S.; Sun, Y.; Sun, Z.; Wang, X.; You, J.; Suo, Y. Determination of triterpenic acids in fruits by a novel high performance liquid chromatography method with high sensitivity and specificity. Food Chem. 2014, 146, 264-269. 
8. Wang, A.; Li, G.; You, J.; Ji, Z. A new fluorescent derivatization reagent and its application to free fatty acid analysis in pomegranate samples using HPLC with fluorescence detection. J. Sep. Sci. 2013, 36, 3853-3859.

9. Bielawska, K.; Dziakowska, I.; Roszkowska-Jakimiec, W. Chromatographic determination of fatty acids in biological material. Toxicol. Mech. Methods 2010, 20, 526-537.

10. Li, A.; Ha, Y.; Wang, F.; Li, W.; Li, Q. Determination of thermally induced trans-fatty acids in soybean oil by attenuated total reflectance fourier transform infrared spectroscopy and gas chromatography analysis. J. Agric. Food Chem. 2012, 60, 10709-10713.

11. Bogusz, S.J.; Hantao, L.W.; Braga, S.C.; de Matos França, V.C.; da Costa, M.F. Solid-phase microextraction combined with comprehensive two dimensional gas chromatography for fatty acid profiling of cell wall phospholipids. J. Sep. Sci. 2012, 35, 2438-2444.

12. Hori, K.; Matsubara, A.; Uchikata, T.; Tsumura, K.; Fukusaki, E.; Bamba, T. High-throughput and sensitive analysis of 3-monochloropropane-1,2-diol fatty acid esters in edible oils by supercritical fluid chromatography/tandem mass spectrometry. J. Chromatogr. A 2012, 1250, 99-104.

13. Aslan, M.; Ozcan, F.; Aslan, B., Yücel, G. LC-MS/MS analysis of plasma polyunsaturated fatty acids in type 2 diabetic patients after insulin analog initiation therapy. Lipidis Health Dis. 2013, 12, 169.

14. Derogis, P.B.; Freitas, F.P.; Marques, A.S.; Cunha, D.; Appolinário, P.P.; de Paula, F. Detection and quantification of Hydroperoxy and Hydroxydo-cosahexaenoic acids as a tool for lipidomic analysis. PLoS One 2013, 8, e77561.

15. Le Faouder, P.; Baillif, V.; Spreadbury, I.; Motta, J.P.; Rousset, P.; Chêne, G. LC-MS/MS method for rapid and concomitant quantification of pro-inflammatory and pro-resolving polyunsaturated fatty acid metabolites. J. Chromatogr. B 2013, 932, 123-133.

16. Takahashi, H.; Suzuki, H.; Suda, K.; Yamazaki, Y.; Takino, A.; Kim, Y.I. Long-chain free fatty acid profiling analysis by liquid chromatography-mass spectrometry in mouse treated with peroxisome proliferator-activated receptor a agonist. Biosci. Biotechnol. Biochem. 2013, 77, 2288-2293.

17. Zeng, A.X.; Chin, S.T.; Nolvachai, Y.; Kulsing, C.; Sidisky, L.M.; Marriott, P.J. Characterisation of capillary ionic liquid columns for gas chromatography mass spectrometry analysis of fatty acid methyl esters. Anal. Chim. Acta 2013, 803, 166-173.

18. Valianpour, F.; Selhorst, J.J.; van Lint, L.E.; van Gennip, A.H.; Wanders, R.J.; Kemp, S. Analysis of very long-chain fatty acids using electrospray ionization mass spectrometry. Mol. Genet. Metab. 2003, 79, 189-196.

19. Byss, M.; Tríska, J.; Elhottová, D. GC-MS-MS analysis of bacterial fatty acids in heavily creosote-contaminated soil samples. Anal. Bioanal. Chem. 2007, 387, 1573-1577.

20. Oursel, D.; Loutelier-Bourhis, C.; Orange, N.; Chevalier, S.; Norris, V.; Lange, C.M. Identification and relative quantification of fatty acids in Escherichia coli membranes by gas chromatography/mass spectrometry. Rapid Commun. Mass Spectrom. 2007, 21, 3229-3233.

21. Catarina, L.S.; José, S.C. Profiling of volatiles in the leaves of Lamiaceae species based on headspace solid phase microextraction and mass spectrometry. Food Res. Int. 2013, 51, 378-387.

22. Mahinda, W.; Thava, V.; Feral, T.; Kevin, S. Volatile flavour composition of cooked by-product blends of chicken, beef and pork: A quantitative GC-MS investigation. Food Res. Int. 2001, 34, $149-158$. 
23. Diana, A.; Olga, G.; Iciar, A.; José, B. Analysis of volatile compounds by GC-MS of a dry fermented sausage: Chorizo de Pamplona. Food Res. Int. 2001, 34, 67-75.

24. Dodds, E.D.; McCoy, M.R.; Rea, L.D.; Kennish, J.M. Gas chromatographic quantification of fatty acid methyl esters: Flame ionization detection vs. electron impact mass spectrometry. Lipids 2005, 40, 419-428.

25. Saliu, F.; Orlandi, M. In situ alcoholysis of triacylglycerols by application of switchable-polarity solvents. A new derivatization procedure for the gas chromatographic analysis of vegetable oils. Anal. Bioanal. Chem. 2013, 405, 8677-8684.

26. Igarashi, M.; Tsuzuki, T.; Kambe, T.; Miyazawa, T. Recommended methods of fatty acid methylester preparation for conjugated dienes and trienes in food and biological samples. $J$. Nutr. Sci. Vitaminol. 2004, 50, 121-128.

27. Box, G.E.P.; Wlson, K.B. On the experimental attainment of optimum conditions. J. R. Stat. Soc. 1951, 13, 1-45.

28. Luo, C.; Chen, Y.S. Optimization of extraction technology of Se-enriched Hericium erinaceum polysaccharides by Box-Behnken statistical design and its inhibition against metal elements loss in skull. Carbohydr. Polym. 2010, 82, 845-860.

29. Jiang, J.; Feng, L.; Li, J.; Sun, E; Ding, S.M.; Jia, X.B. Multielemental composition of suet oil based on quantification by ultrawave/ICP-MS coupled with chemometric analysis. Molecules 2014, 19, 4452-4465.

(C) 2015 by the authors; licensee MDPI, Basel, Switzerland. This article is an open access article distributed under the terms and conditions of the Creative Commons Attribution license (http://creativecommons.org/licenses/by/4.0/). 